\title{
Basic Information About Etiology of the So-Called Idiopathic Scoliosis. New Classification, Therapy. Causal Prophylaxis
}

\author{
T Karski* \\ Department of Biological sciences, Poland
}

*Corresponding author: T Karski, Department of Biological sciences, Vincent Pol

University in Lublin, Poland.

Received Date: March 03, 2020

Published Date: March 31, 2020

\begin{abstract}
The biomechanical causes of the "Idiopathic Scoliosis", in new description "So-Called Idiopathic Scoliosis" - were described in years 1995-2007 in Lublin, Poland, but the observation and research was from 1984. All old conception about etiology were never correct because had no answered to all questions about "idiopathic scoliosis". In my research I found that etiology is based / conneted on biomechanical factors-"permanent standing 'at ease' on the right leg" and walking / gait. These two biomechanical factors appear because of the asymmetry of hips movement-in right hip is limited adduction and often internal rotation and extension-in straight position of right hips. The restriction of movement of the right hip is one of the eight symptoms of the "Syndrome of Contracture and Deformities (SofCD) according to Prof. Hans Mau and Lublin observations. The found etiology give the possibility to describe the classification, rules of therapy and prophylactics.
\end{abstract}

Keywords: Scoliosis; Biomechanical etiology; New classification; Therapy; Prophylaxis

\section{Introduction}

Importance in etiology of the so-called idiopathic scoliosis. [Adolescent Idiopathic Scoliosis (AIS)].

In the years 1984-1995, in examination of many children $(\mathrm{N}$ 2500), I found that scoliosis is connected with the asymmetrical movement of hips and next with function-permanent "standing 'at ease' on the right leg" and "gait". The limitation of adduction of the right hip, or even abduction contracture of this joint 5 to 10 degree is one of the symptoms of "The Syndrome of Contractures and Deformities" [SofCD] according to Prof. Hans Mau from Tübingen, Germany [1-18] and Lublin observations [19-29]. The straight position in examination is similar to the "standing position" or to the "stance phase in walking" and these "moments" play deciding role in development of scoliosis through function-"standing" and "gait" (Figure 1). The deciding is-that "standing 'at ease' on the right leg" is permanent because is safe, light, comfortable, stabile (words of children) and because of this the right leg is taken for standing (Figure 1).

\section{Additionally causes in development of scoliosis}

In many children with scoliosis can appear "neurological dysfunctions" and there are connected with the Minimal Brain Dysfunctions (MBD) in children from complicated pregnancy or delivery. In some scoliosis children I could see:

a. Extension contracture of trunk-here we should remember that in "S" scoliosis in 1st epg group/type and in "I" scoliosis in 3rd epg group/type-the spine is stiff in "extension position",

b. Anterior tilt of pelvis-diminish stability between pelvis and spine-enable easy development of scoliosis,

c. Laxity of joints - easy development of scoliosis.

Material. In the years 1984-2019, more than 2500 patients with scoliosis were observed and treated. In all these cases I could found the asymmetry of the movement of the hips-limited adduction of the right hip in extension position of the joint. The control group-350 
children-were presented by parents with the question about scoliosis-in these all cases the movement of hips was symmetrical and was no spine deformity [30-38].

\section{Historical dates about etiology of scoliosis}

- 1995-first lecture about biomechanical etiology of the so-called idiopathic scoliosis during Orthopedic Congress in Szeged, Hungary.

- 1996-first publication about biomechanical etiology of scoliosis in Orthopädische Praxis in Germany: T. Karski [1996] Kontrakturen und Wachstumstorungen im Huft- und Beckenbereich in der Ätiologie der sogenannten „idiopatischen Skoliosen"-biomechanische Überlegungen, Orthopädische Praxis 32, 3 (1996) 155-160

- 2001 and 2004-describing in new classification three etiopathological groups (epg) and four types of scoliosis: 3a/ "S" scoliosis in 1st epg, 3b/ "C" and 3c/ "S" scoliosis in $2^{\text {nd }}$ epg., 3d/ "I" scoliosis in $3^{\text {rd }}$ epg. In this type the spine is stiff, there are no curves or small ones.

- 2006-the ultimate description of the "type of hips movement" and the "type of scoliosis".

- 2007-description of indirect influences coming from Central Nervous System (CNS) in children with Minimal Brain Dysfunction (MBD) and explanation the question-why the fool blind children have no scoliosis. Answer: their gait is without lifting of legs, with all time stable pelvis and standing is on the both legs with symmetrical loading.

\section{New classification-Three groups and four types of scoliosis (Figure 1) [8 - 28]}

The type of spine deformity is connected with "model of hips movement" and etiological factors-"gait" and "standing 'at ease' on the right leg".

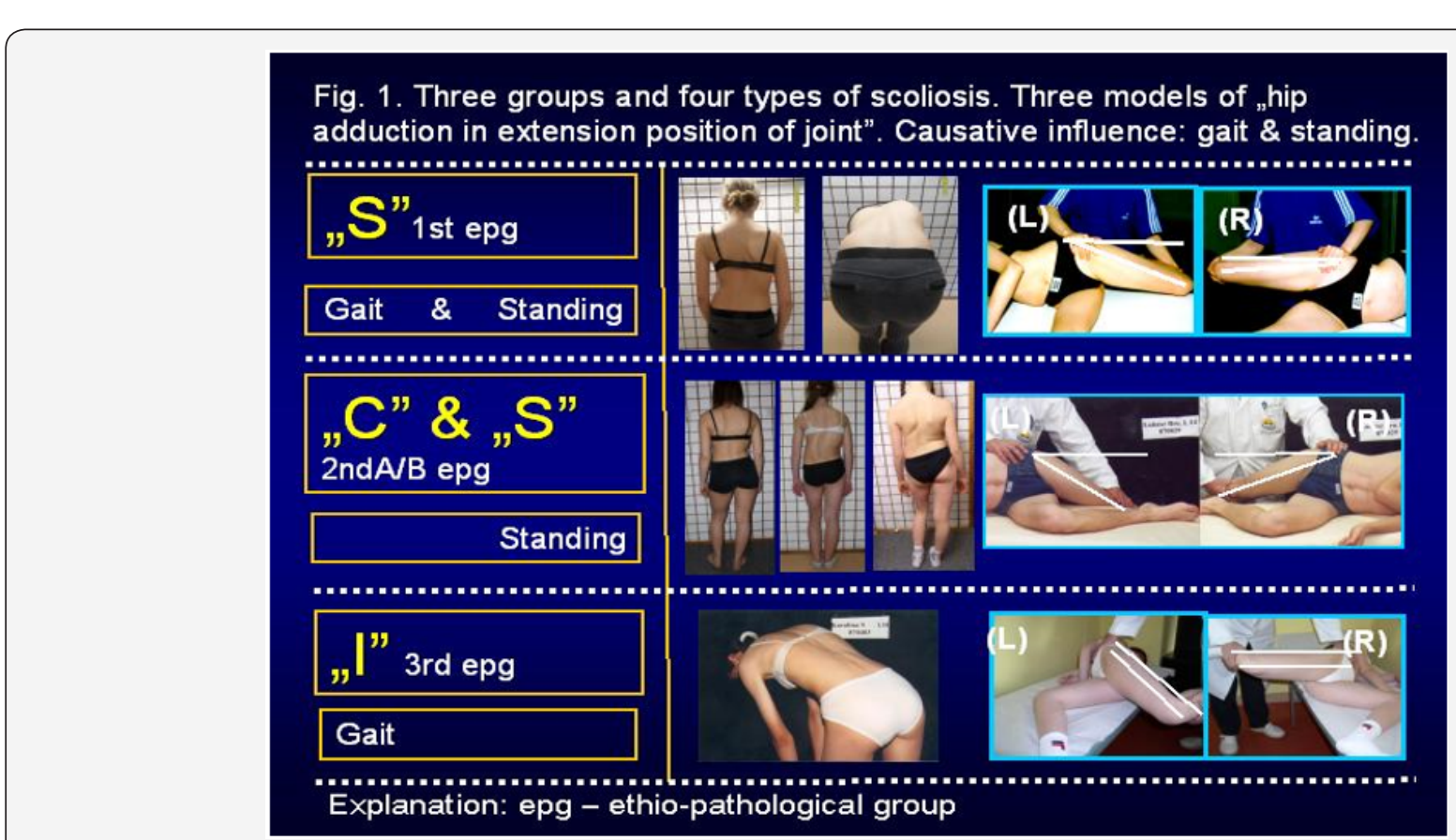

Figure 1: Three groups and four types of scoliosis. Three models of „hip adduction in extension position of joint”. Causative influence: gait \& standing.

1. Scoliosis 3D - "S" 1st etiopathological group (epg) - double curve. Stiff spine. Rib hump on the right side of the thorax. Specific model of hip movements-maximally limited movement of right hip and full movement of the left hip. Connection with "gait" and permanent "standing 'at ease' on the right leg". Mostly-rapid progression.

2. Scoliosis 1D or 2D - "C" $2^{\text {nd }} / A$ epg-one curve-lumbar left convex. Flexible spine. Specific model of hip movementsminimally limited movement. of the right hip and full movement of the left hip. Connected with permanent standing „at ease' on the right leg. This type of scoliosis is without progression.

3. Scoliosis 2D or 3D "S" $2^{\text {nd }} / \mathrm{B}$ epg-two curves. Specific model of hip movements-minimally limited movement of the right hip and full movement of the left hip. Connection with permanent standing 'at ease' on the right leg and additionally with laxity of joints or / and previous, harmful exercises. In the $2^{\text {nd }} / \mathrm{A}$ and $2^{\text {nd }} / \mathrm{B}$ types of scoliosis - the spine is flexible. This type of scoliosis is with moderate progression.

4. Scoliosis 2D or 3D - "I" 3rd epg. Specific model of hip movements-maximally limited movement of right hip and maximally or partially limited movement of the left hip. Deformity has the form of a stiff spine. No curves or small ones. The only cause is gait. Clinical symptoms are "stiffness of the spine in children" and "pain syndromes in adults". Stiffness, like in the 1st type of scoliosis, is connected with "distortion movement" of intervertebral joints of the spine in every step during gait [39-41]. 


\section{Test in Scoliosis}

In diagnosis of scoliosis there are important old test but very important are new ones.

- $\quad$ Asymmetry of waist (old).

- $\quad$ Adams test-"bending test for scoliosis" (old).

- $\quad$ Lublin test-“side bending test for scoliosis" (new).

- Checking the adduction and internal rotation of the both hips in extension position of joint-especially of right hip (new).

- $\quad$ Checking of flexion contracture of hips (new).

- Checking of habit of standing-'at ease'-on left or on right $\operatorname{leg}($ new).

- Checking of "possible laxity of joints" (old and new).

\section{Proper therapy (Figure 2)}

In therapy there are very important flexion exercises - stretching exercises for hips-especially for right hip-for spine to cure the all "contracture" regions- its mean shortening of soft tissues-muscles, fascias, tendons, capsules of joints. All these exercises are similarly or the same like in karate, taekwondo, aikido, kung fu or yoga. Here I would like to inform that flexion exercises in the treatment of scoliosis in Poland (1960-1970) were introduced by Prof. Stefan Malawski from Warsaw / Otwock (31-33 and personal discussions).

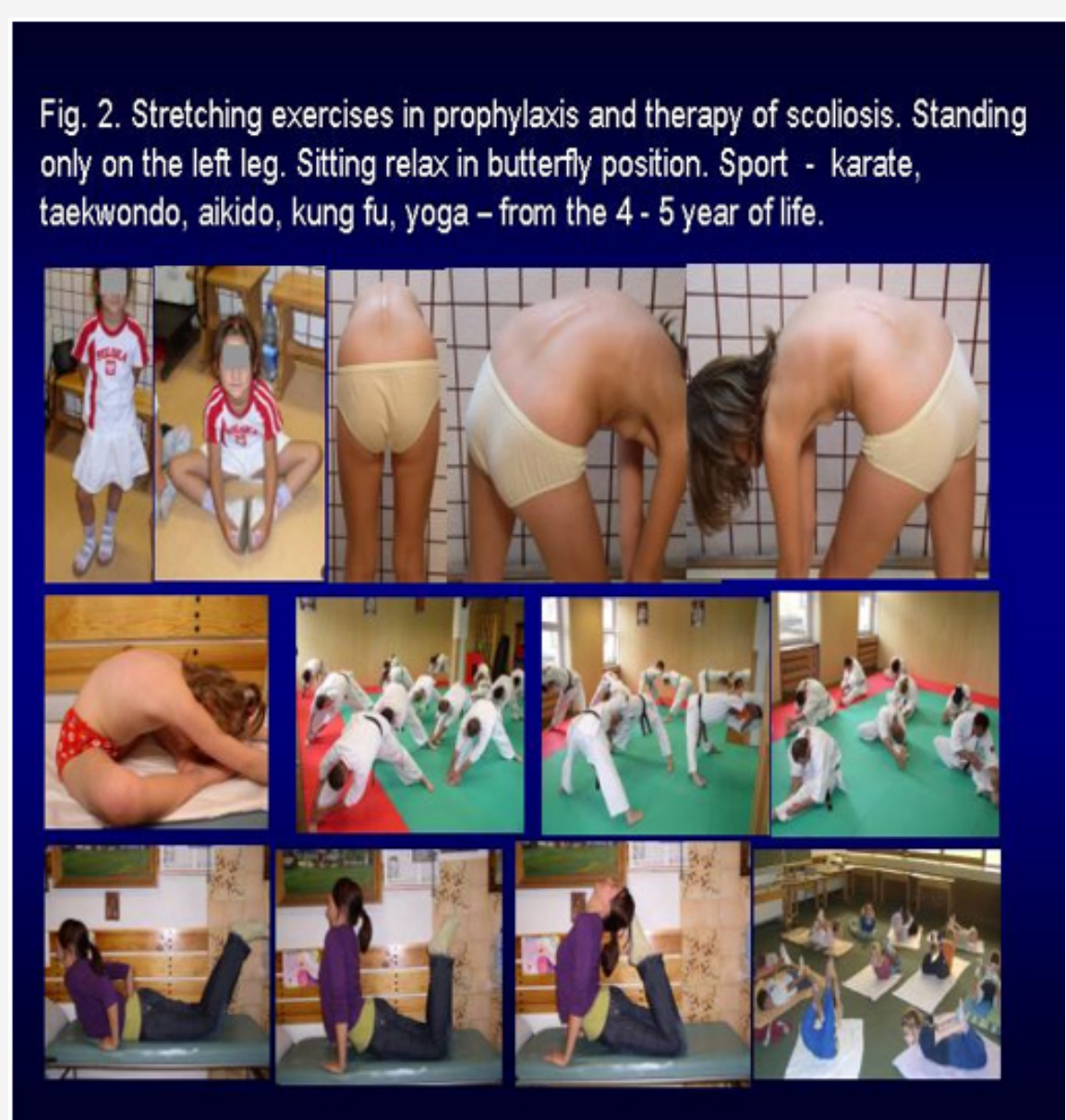

Figure 2: Stretching exercises in prophylaxis and therapy of scoliosis. Standing only on the left leg. Sitting relax in butterfly position. Sport karate, taekwondo, aikido, kung fu, yoga - from the $4-5$ year of life.

\section{Causal prophylaxis from the 4-5 years of life}

- Standing at ease only on the left leg,

- $\quad$ Sitting in "butterfly position" (term from karate) and with relaxed spine-never straight up,

- $\quad$ Sleeping in the embryo position,

- $\quad$ Active participation in sports at school and additionally in clubs - the best are karate, kung fu, taekwondo, aikido, yoga,

- Physiotherapy / Kinesio-therapy to obtain full, symmetrical movement of both hips and movements of the spine-flexion, deviation, rotation.

- Especially important is to recover the full adduction and internal rotation movement of the right hip. It is new important aim for physiotherapy.

\section{Conclusion}

- The etiology of the so-called idiopathic scoliosis is strictly biomechanical.

- The pathological "model of hip movements" plays an important role in the development of scoliosis (T. Karski, 2006) 
and influence coming from function-"standing 'at ease' on the right leg" and "gait".

- There are three groups and four types of scoliosis-see "new classification".

- $\quad$ The children in/at the world wait for new therapy and causal prophylaxis in the So-Called Idiopathic Scoliosis.

\section{Acknowledgement}

I would like to express my many thanks to Miss Honorata Menet for correction of the some parts of article.

\section{Conflicts of Interest}

No conflicts of interest.

\section{References}

1. Mau H [1979] For the etiopathogenesis of scoliosis, hip dysplasia and torticollis in infancy. Magazine f. 294 Orthop 5: 601-605.

2. Mau H [1982] The Atiopatogenesis of Scoliosis, Orthopedist's Library Enke Verlag Stuttgart 33(1): 296-297.

3. Normelly H [1985] Asymmetric rib growth as an aetiological factor in idiopathic scoliosis in adolescent girls. 298 Stockholm 1: 103-299.

4. T Karski [1996] Contractures and growth disorders in the hip and pelvic area in the etiology of the so-called "idiopatic scoliosis"-biomechanical considerations, orthopedic practice 32(3): 155-160

5. Karski T [2002] Etiology of the so-called "idiopathic scoliosis". Biomechanical explanation of spine deformity. Two 272 groups of development of scoliosis. New rehabilitation treatment. Possibility of prophylactics. Studies in 273 Technology and Informatics, 91: 37-46.

6. Karski T, Kalakucki J, Karski J [2006] "Syndrome of contractures" (according to Mau) with the abduction contracture of the right hip as causative factor for development of the so-called idiopathic scoliosis. Stud Health Technol Inform 123: 34-39.

7. Karski T [2010] Explanation of biomechanical etiology of the so-called idiopathic scoliosis (1995 - 2007). New 276 clinical and radiological classification" in"Pohybove Ustroji" [Locomotor System] 17(2): 277-278

8. Karski T [2011] Biomechanical Etiology of The So-Called Idiopathic Scoliosis (1995 - 2007) - Connection with 279 "Syndrome of Contractures.Fundamental Information for Paediatricians in Program of Early Prophylactics / 280 Journal of US-China Medical Science, USA, 8(78): 281

9. Karski Tomasz [2010] Biomechanical factors in the etiology of idiopathic dinominated scoliosis. New 282 classifications. New clinical tests and new conservative treatment and prophylaxis, Physiotherapy Issues, Mayo- 283 Agosto, paginas 39 (2): 144-152

10. Karski Tomasz [2010] Biomechanical Etiology of the So-called Idiopathic Scoliosis (1995-2007). New Classification: 285 Three Groups, Four Subtypes. Syndrome of Contractures Pan Arab J Orth. Trauma (14)2: 286.

11. Karski Tomasz [2013] Biomechanical Etiology of the So-called Idiopathic Scoliosis (1995 - 2007). Three Groups and 288 Four Types in the New Classification, Journal of Novel Physiotherapies, OMICS Publishing Group, USA, 289(6): 290

12. Karski Jacek, Tomasz Karski [2013] So-Called Idiopathic Scoliosis. Diagnosis. Tests Examples of Children Incorrect 291 Treated. New Therapy by Stretching Exercises and Results. Journal of Novel Physiotherapies, OMICS Publishing 3-2(9): 293

13. Karski Tomasz [2014] Biomechanical Aetiology of the So-Called Idiopathic Scoliosis. New Classification (1995-2007) in Connection with Model of Hips Movements. Global Journal of Medical Research H: Orthopedic and Musculoskeletal System 14(3): 12.
14. Karski Tomasz [2014] Biomechanical Etiology of the So-called Idiopathic Scoliosis (1995 - 2007) - Connection with Syndrome of Contractures Fundamental Information for Pediatricians in Program of Early Prophylactics. Surgical Science 5: 33-38.

15. Karski Tomasz, Karski Jacek [2015] Syndrome of Contractures and Deformities according to Prof. Hans Mau as Primary Cause of Hip, Neck, Shank and Spine Deformities in Babies, Youth and Adults American Research Journal of Medicine and Surgery 1(2).

16. Karski Tomasz, Jacek Karski [2015] Biomechanical etiology of the so-called Idiopathic Scoliosis (1995 -2007). Causative role of gait and permanent standing at ease on the right leg. New classification. Principles of new therapy and causal prophylaxis. Canadian Open Medical Science \& Medicine Journal 1(1): 1-16

17. Karski Jacek, Tomasz Karski, Jarosław Pyrc, MaLgorzata Kulka [2016] Deformations of the feet, knees, hips, pelvis in children and adults with minimal brain dysfunction. causes. treatment. Prophylaxis. Locomotors System 23(2).

18. Karski Tomasz [2017] Physiotherapy-Correct, or Incorrect, Based on Wrong Principles of Treatment'. Example for Spine, Hip, Knee, Shank and Feet. Crimson Publishers 21.

19. Karski Tomasz, Jacek Karski, Klaudia Karska, Katarzyna Karska, Honorata Menet [2018] Pediatric Prophylaxis Program of Motor System Deformations and Illnesses in Children. Problems of Spine, Hips, Knees and Feet.

20. Karski Tomasz, Jacek Karski, Katarzyna Karska, Klaudia Karska and Honorata Menet [2018] Prophylactic Rules for Newborns, Babies, Children and Adults in problems of Hip, Knee, Shank, Feet and Spine, Online Journal Crimson Publishers.

21. Karski Tomasz, Jacek Karski [2016] Low back pain-a neurological and orthopedic problem. Symptoms. Causes. Treatment. Back painneurology-orthopedic problems. Clinic, causes, therapy and prophylaxis. Advances in Practical Neurology. Czelej Publishing House 4: 9 -16

22. Karski Jacek, Karski Tomasz [2016] Imperfect hips As a Problem at an Older Age. Early and Late Prophylactic Management before Arthrosis. Jacobs Journal of Physiotherapy and Exercises. (2)1: 7

23. Karski Tomasz [2018] Biomechanical Aetiology of the So-called Adolescent Idiopathic Scoliosis (AIS). Lublin Classification (1995-2007). Causative Influences Connected with Gait and "Standing at ease on the Right Leg, Journal of Orthopaedics and Bone Research 10.

24. Karski Tomasz [2019] Biomechanical Etiology of the So-Called Idiopathic Scoliosis, Connection with Syndrome of Contractures and Deformities, Role of Gait and Standing At Ease On the Right Leg in the Development of Spine Deformity, New Treatment, Causal Prophylactics, International Journal of Orthopaedics Research 5

25. Karski Tomasz [2019] Biomechanical Etiology of the So-called Idiopathic Scoliosis (Adolescent Idiopathic Scoliosis [AIS]). New Classification Rules of Therapy and Prophylaxis. Nursing and Health Care Journal 4(1): 4.

26. Burwell G, Dangerfield PH, Lowe T, Margulies J [2000] Spine. Etiology of Adolescent Idiopathic Scoliosis: Current Trends and Relevance to New Treatment Approaches, Hanley \& Belfus, Inc, Philadelphia, 14(2): 324.

27. Dangerfield PH, Dorgan JC, Scutt D, Gikas G, Taylor JF [1995] Stature in Adolescent Idiopathic Scoliosis (AIS) pp. 10.

28. Green NE, Griffin PP [1982] Hip dysplasia associated with abduction contracture of the contralateral hip. JBJS 63(9): 1273-1281.

29. Gruca A, Tylman D [1995] Pathomechanics of lateral curvatures of the spine. Warsaw, Seiten 167:3

30. Heikkila E [1984] Congenital dislocation of the hip in Finland. An epidemiologic analysis of 1035 cases, Acta Orthop Scandinavica 55(2): 125-129.

31. Hensinger RN [1979] Congenital dislocation of the hip. Clinical Symp 31: 270. 
32. Howorth B [1977] The etiology of the congenital dislocation of the hip. Clin Orthop 29: 164-179.

33. Lowe TG, Edgar M, Margulies JY, Miller NH, Raso VJ, et al. [2000] Etiology of idiopathic scoliosis: current trends in research. J Bone Joint Surg Am 82(8): 1157-1168.

34. Malawski Stefan [1992] Epidemiology of scoliosis, Advances in Polish Spondyloorthopedia. 5

35. Malawski Stefan [1992] Own rules for the treatment of low-grade scoliosis, Advances in Polish Spondyloorthopedia.

36. Malawski S. [1994] Own rules for the treatment of low-grade scoliosis in the light of modern views on the etiology and pathogenesis of scoliosis, Chir. Tools. Movement and Orthop Half 59(3):189-197.
37. Rąpala K, Tylman D [1995] Pathomechanics of lateral curvatures of the spine. Publishing House Severus, Warsaw, Seiten 167.

38. Stokes IAF [1999] Studies in Technology and Informatics, Research into Spinal Deformities IOS Press 1999, Amsterdam, Berlin, Oxford, Tokyo, Washington DC 2(59): 1-385.

39. Sevastik J, Diab K [1997] Studies in Technology and Informatics, Research into Spinal Deformities 1, Vol. 37., IOS 300 Press 1997, Amsterdam, Berlin, Oxford, Tokyo, Washington, DC 1-509. 301

40. Tylman D. [1995] Patomechanika bocznych skrzywień kręgosłupa, Wydawnictwo Severus, Warszawa, 1995, Pages 167.

41. www.ortopedia.karski.lublin.pl [from 2006] 